\title{
Efeito de doses de nitrogênio na severidade da murcha-de-curtobacterium em cultivares de feijoeiro comum
}

\author{
Gustavo de Faria Theodoro ${ }^{1}$, Antonio Carlos Maringoni ${ }^{2,3}$
}

\begin{abstract}
${ }^{1}$ Epagri/Centro de Pesquisa para Agricultura Familiar, CP 791, 89801-970, Chapecó, SC; ${ }^{2}$ Faculdade de Ciências Agronômicas, Unesp, Departamento de Produção Vegetal, Setor de Defesa Fitossanitária, CP 237, 18603-970, Botucatu, SP; ${ }^{3}$ Bolsista CNPq. Parte da Tese de Doutorado do primeiro autor, apresentada à Faculdade de Ciências Agronômicas/Unesp, Botucatu, SP (2004).
\end{abstract}

Autor para correspondência: Gustavo de Faria Theodoro. <theodoro@epagri.rct-sc.br>

Data de chegada: 02/10/2004. Aceito para publicação em 26/04/2005.

\begin{abstract}
Theodoro, G.F.; Maringoni, A.C. Effect of nitrogen levels in the severity of bacterial wilt in common bean cultivars. Summa Phytopathologica, v.32, n. 2, p. 131-138, 2006.

It was evaluated the influence of nitrogen $(\mathrm{N})$ levels in the severity of bean bacterial wilt, caused by Curtobacterium flaccumfaciens pv. flaccumfaciens, in the cultivars IAC Pyatã, IPR 88 - Uirapuru, and SCS 202 - Guará, under greenhouse conditions. The treatments

lower or higher than that, using urea as $\mathrm{N}$ source. The higher levels of $\mathrm{N}$ increased the progress of the bacterial wilt only in the cultivar IAC Carioca Pyatã. The N content in the plant aerial part did not interfere with the dry mass weight of any cultivars tested.
\end{abstract} consisted of the recommended level of $\mathrm{N}$ and rates $25 \%$ and $50 \%$

Additional keywords: Phaseolus vulgaris, Curtobacterium flaccumfaciens pv. flaccumfaciens, mineral nutrition, urea, bacterium.

\section{RESUMO}

Theodoro, G.F.; Maringoni, A.C. Efeito de doses de nitrogênio na severidade da murcha-de-curtobacterium em cultivares de feijoeiro comum. Summa Phytopathologica, v.32, n. 2, p. 131-138, 2006.

Foi avaliada a influência de doses de nitrogênio $(\mathrm{N})$ na severidade da murcha-de curtobacterium do feijoeiro, causada por Curtobacterium flaccumfaciens pv. flaccumfaciens, nas cultivares IAC Pyatã, IPR 88 - Uirapuru e SCS 202 - Guará, em condições de casa-devegetação. Os tratamentos foram a dose recomendada de $\mathrm{N}$ e outras 25 e $50 \%$ abaixo e acima desta, empregando-se uréia. O aumento de doses de $\mathrm{N}$ influenciou positivamente o progresso da murcha-decurtobacterium somente na cultivar IAC Carioca Pyatã, incrementou a quantidade de $\mathrm{N}$ na parte aérea e não interferiu no peso da matéria seca das plantas de todas as cultivares avaliadas.

Palavras-chave adicionais: Phaseolus vulgaris, Curtobacterium flaccumfaciens pv. flaccumfaciens, nutrição mineral, uréia, bactéria.

Entre as doenças de etiologia bacteriana que incorrem na cultura do feijoeiro (Phaseolus vulgaris L.), a murcha-de-curtobacterium, causada por Curtobacterium flaccumfaciens pv.flaccumfaciens (Hedges) Collins \& Jones, tem se tornado uma séria ameaça no Brasil. Esta doença foi primeiramente constatada em Dakota do Sul, E.U.A., em 1920, causando morte em cerca de $90 \%$ das plantas cultivadas (8). No território brasileiro, foi inicialmente relatada em lavouras de feijão no Estado de São Paulo (14) e, atualmente, pode ser encontrada no Paraná, Santa Catarina, Goiás e Distrito Federal $(9,28)$. No Estado de Santa Catarina, a murcha-de-curtobacterium foi constatada em diversas localidades produtoras de feijão, indicando a necessidade de me- didas de controle (27). Os sintomas da murcha-de-curtobacterium em feijoeiro são o amarelecimento, nanismo, murcha, escurecimento vascular e morte, com a planta podendo não ultrapassar a fase de plântula. Pode haver uma descoloração amarela ou púrpura em sementes infectadas (7). O seu controle tem sido baseado no uso de sementes sadias, variedades resistentes e rotação de culturas (7). Porém, Theodoro \& Maringoni (27) constataram que todas as cultivares recomendadas para o Estado de Santa Catarina foram suscetíveis à murcha-de-curtobacterium e que as cultivares IAC Carioca Akytã, IAC Carioca Aruã e IAC Carioca Pyatã foram resistentes. Entre os genótipos suscetíveis, aos 25 dias após a inoculação (DAI), a cultivar 
IPR 88 - Uirapuru obteve elevada nota de severidade e a 'SCS 202 - Guará' mostrou um maior período de incubação. O tratamento de sementes e a pulverização de acibenzolar-S-methyl nas folhas não foram eficazes na indução de resistência em cultivares de feijoeiro $(23,24)$.

A aplicação de fertilizantes é uma prática usual no processo de produção agrícola, sendo que os macro e micro nutrientes estão intimamente ligados ao desenvolvimento, à produtividade e mudanças na fisiologia do vegetal (6). Conseqüentemente, os nutrientes minerais podem exercer um efeito secundário nas plantas, como aumentar ou diminuir a resistência ou a tolerância a patógenos (30). O nitrogênio $(\mathrm{N})$ é um nutriente extremamente importante para os vegetais, pois se combina em cadeias orgânicas, se encontra em mais de uma centena de aminoácidos e, conseqüentemente, participa da constituição da clorofila e de proteínas com ação enzimática, com atuação em processos metabólicos (16). Existem diversos relatos sobre a influência do $\mathrm{N}$ sobre a incidência e severidade de doenças de plantas (1, 2, $15,18)$

O objetivo deste trabalho foi avaliar o patossistema feijoeiro- $C$. flaccumfaciens pv. faccumfaciens, o acúmulo de matéria seca e a concentração de nitrogênio, fósforo $(\mathrm{P})$, potássio $(\mathrm{K})$, cálcio $(\mathrm{Ca})$ e magnésio $(\mathrm{Mg})$ na parte aérea dos feijoeiros 'IAC Carioca Pyatã', 'IPR 88 - Uirapuru' e 'SCS 202 - Guará', inoculados ou não com $C$. $f$. pv. flaccumfaciens e cultivados sob diferentes doses de $\mathrm{N}$.

\section{MATERIAL E MÉTODOS}

Foi avaliado o efeito de diferentes doses de nitrogênio na severidade da murcha-de-curtobacterium do feijoeiro, nas cultivares IAC Carioca Pyatã, IPR 88 - Uirapuru e SCS 202-Guará. Foram conduzidos três ensaios simultâneos para cada cultivar, em condições de casa-de-vegetação. No primeiro, retirou-se a parte aérea das plantas aos 10 dias após a semeadura (DAS), que foi seca em estufa de circulação forçada de ar a $60^{\circ} \mathrm{C}$, e aferido o peso da matéria seca. Posteriormente, foram coletadas amostras compostas por 15 plantas de feijoeiro, distribuídas em cinco vasos, e enviadas para ser realizada análise química. No segundo ensaio, as plantas foram picadas no epicótilo aos 10 DAS, por meio de uma alça reta embebida com água destilada esterilizada, representando o tratamento testemunha e conduzidas por mais 25 dias. Neste momento, realizou-se a avaliação da severidade da murcha-de-curtobacterium e a parte aérea das plantas foi seca em estufa de circulação forçada de ar a $60^{\circ} \mathrm{C}$, pesada e destinada para análise química. Já no terceiro ensaio, as plantas foram inoculadas com o isolado FJ 36, de $C$. flaccumfaciens pv. flaccumfaciens, aos dez das, por meio de duas picadas no epicótilo com uma alça reta previamente umedecida em colônias bacterianas, cultivadas por $96 \mathrm{~h}$ a $28^{\circ} \mathrm{C}$, em placa de Petri contendo meio de cultura nutriente-sacarose-ágar ou N.S.A. (extrato de carne $-3,0 \mathrm{~g}$, peptona - 5,0 g, ágar - 15,0 g, sacarose $-5,0 \mathrm{~g}$, água destilada q.s.p. - $1000 \mathrm{~mL}$ ), conforme a metodologia empregada por Maringoni (13). A avaliação dos sintomas ocorreu aos 5, 10, 15, 20 e 25 DAI, empregando-se a escala descritiva adaptada por Maringoni (13). As reações de resistência e de suscetibilidade foram consideradas para notas médias de severidade até 2 e superiores a 2,1, respectivamente. A partir dos valores de severidade obtidos, foi estimada a área abaixo da curva de progresso da murcha-de-curtobacterium em cada genótipo, de acordo com a fórmula: AACPMC $=\Sigma\left\{\left[\left(\mathrm{Y}_{1}+\mathrm{Y}_{2}\right)\right\}\right.$ $\left.2]^{*} \Delta \mathrm{t}\right\}$, onde $\mathrm{Y}_{1}$ e $\mathrm{Y}_{2}$ corresponderam aos valores de severidade para avaliações sucessivas dentro do mesmo bloco e $\Delta \mathrm{t}$, o intervalo de tempo entre elas. A condução deste ensaio ocorreu até os 25 dias após a inoculação e, após a última avaliação da severidade da doença, foi retirada a parte aérea e procederam-se a aferição da matéria seca e o encaminhamento das amostras para análise química.

O solo empregado foi coletado em barranco e possuía as seguintes características: argila $(\%)=61 ; \mathrm{pH}$ (água 1:1) $=6,9$; índice $\mathrm{SMP}=7 ; \mathrm{P}\left(\mathrm{mg} \cdot \mathrm{L}^{-1}\right)=5,2 ; \mathrm{K}\left(\mathrm{mg} \cdot \mathrm{L}^{-1}\right)=36 ; \mathrm{M} . \mathrm{O} .(\%)=1,0$; $\mathrm{Al}\left(\right.$ cmolc. $\left.\mathrm{L}^{-1}\right)=0,0 ; \mathrm{Ca}\left(\right.$ cmolc. $\left.\mathrm{L}^{-1}\right)=3,9$ e Mg $\left(\right.$ cmolc. $\left.\mathrm{L}^{-1}\right)=2,4$. A análise textural mostrou a presença de $62,4 \%$ de argila, 34,2\% de silte e $3 \%$ de areia fina. Baseando-se nas recomendações de adubação para o Estado de Santa Catarina (5), foi feita a adubação básica no momento anterior à distribuição do solo nos vasos, empregando-se o proporcional a $75 \mathrm{~kg} \cdot \mathrm{ha}^{-1}$ de $\mathrm{P}_{2} \mathrm{O}_{5}$, na forma de superfosfato triplo. Procurou-se distribuir este adubo de forma homogênea no solo com o auxílio de uma betoneira. A quantidade de $\mathrm{K}_{2} \mathrm{O}$ foi parcelada e aplicada em cobertura no momento das adubações, empregando-se $90 \mathrm{~kg}$ de $\mathrm{K}_{2} \mathrm{O}^{-\mathrm{ha}^{-1}}$ na forma de cloreto de potássio, metade aos 10 dias após a semeadura (DAS) e o restante aos 17 DAS. Os tratamentos foram: + $50 \%$ da dose recomendada de $\mathrm{N}\left(150 \mathrm{~kg} \cdot \mathrm{ha}^{-1}\right) ;+25 \%$ da dose recomendada de $\mathrm{N}$ (125 kg.ha $\left.{ }^{-1}\right)$; dose recomendada de $\mathrm{N}$ (100 kg.ha-1); - 25\% da dose recomendada de N (75 kg.ha-1) e - 50\% da dose recomendada de $\mathrm{N}\left(50 \mathrm{~kg} \cdot \mathrm{ha}^{-1}\right)$, na forma de uréia e aplicados na superfície do solo. $\mathrm{O}$ delineamento experimental empregado foi o de blocos ao acaso com cinco repetições, sendo que cada parcela foi representada por um vaso contendo três plantas de feijoeiro.

As sementes das cultivares foram imersas em solução contendo benomyl a 0,25 g.L $\mathrm{L}^{-1}$, durante 5 minutos e colocadas para pré-germinar, a $25^{\circ} \mathrm{C}$, em papel toalha umedecido, até a emissão da radícula. As sementes pré-germinadas foram transplantadas para os sacos plásticos, com 5L de terra de barranco corrigida e adubada. A adubação nitrogenada foi parcelada em duas vezes, aos 10 e aos 17 dias após a semeadura (DAS), aplicada diretamente na superfície do solo úmido, seguido de rega. Procurou-se manter o solo sempre com uma umidade próxima à capacidade de campo, durante toda a condução do experimento.

Os resultados obtidos foram submetidos à análise de variância e, quando significativos, à análise de regressão polinomial.

As análises químicas da parte aérea foram realizadas conforme metodologia descrita por Tedesco et al. (26) modificada. As amostras foram obtidas por meio de cinco repetições, contendo três plantas cada. Foi coletada toda a parte aérea das plantas sadias, na época de inoculação, com nove dias e aos 25 dias e inoculadas, na última avaliação dos sintomas da murchade-curtobacterium (25 dias). Estas foram lavadas em água de torneira e, posteriormente, em água destilada em bandejas de plástico por duas vezes consecutivas, para que fossem eliminadas partículas de solo e resíduos que pudessem interferir nos resultados. Após o acondicionamento das amostras em sacos de papel, estas foram destinadas para secagem em estufa com circulação forçada a ar, a temperatura de $60^{\circ} \mathrm{C}$. A preparação da amostra foi obtida por dupla moagem, triturando-se inicialmente o material seco em moinhos de facas até passar em malha de 
2-3 mm de diâmetro e passagem da mostra em moinho tipo 'Wilie' (orifícios de $0,5 \mathrm{~mm}$ de diâmetro).

Foram realizadas análises dos nutrientes N, P, K, Ca e Mg. O $\mathrm{N}$ foi analisado mediante extração por meio de digestão sulfúrica e determinado pelo método semi-micro Kjeldahl, utilizandose catalisadores e alta temperatura $\left(350-375^{\circ} \mathrm{C}\right)$. Na determinação do P total, a digestão da amostra foi realizada por meio do método nítrico-perclórico e a determinação em espectrofotometria, com uso de redutor vanadato/molibdato. Os nutrientes K, $\mathrm{Ca}$ e $\mathrm{Mg}$ foram determinados com espectrofotômetro de absorção atômica.

\section{RESULTADOS E DISCUSSÃO}

Os resultados indicaram que o solo empregado neste ensaio não influenciou significativamente no acúmulo de matéria seca até o momento em que os diferentes tratamentos foram empregados (Tabela 1). Porém, a média da matéria seca acumulada, em todos os tratamentos e nas plantas da cultivar SCS 202 - Guará, foi 18,2 \% e 30,0 \% acima daquelas obtidas pelas cultivares IPR 88 - Uirapuru e IAC Carioca Pyatã, respectivamente. Pode ser que estas diferenças estejam relacionadas com o porte ou o hábito de crescimento das cultivares avaliadas. Porém, aventa-se a hipótese que a diferença de desenvolvimento entre as cultivares foi causada pelas diferentes marchas de absorção de nutrientes ainda na fase de plântula, uma vez que a quantidade de nutrientes das amostras foi maior nos tecidos das cultivares SCS 202-Guará, seguidos pela IAC Carioca Pyatã e IPR 88 - Uirapuru. Esta hipótese corrobora com Rosolem (20), que afirmou a possibilidade de haver diferença na marcha de absorção de nutrientes entre genótipos de feijão e a necessidade deste tipo de estudo em cultivares recém-lançadas. $\mathrm{O}$ mesmo foi observado por Yamazaki et al. (29), que observaram diferenças na absorção de nutrientes em plântulas de 23 cultivares de tomateiro, com variados graus de resistência e suscetibilidade a Ralstonia solanacearum. Aos 10 dias após a semeadura, percebeu-se que as plântulas ainda se apresentavam com cotilédones enrugados aderidos ao caule e suas raízes provavelmente absorviam os nutrientes do solo em pequenas quantidades. Assim, pode-se afirmar que o $\mathrm{N}$ mineral e/ou orgânico contido no solo, aparentemente não influenciou no acúmulo de $\mathrm{N}$ na parte aérea das plantas aos 10 DAS, antes das adubações em cobertura com uréia. Não foi realizada análise de variância nem de regressão para se detectar qualquer influência do substrato na quantidade de $\mathrm{N}$, antes das adubações em cobertura, porque foi utilizada uma amostra composta pela parte aérea de 15 plântulas, distribuídas uniformemente em cinco vasos com $5 \mathrm{~L}$ de solo, para que fosse obtido o peso necessário para se proceder as análises químicas.

Os sintomas da murcha-de-curtobacterium foram manifestados em todas as plantas inoculadas, independentemente da cultivar, mostrando que houve condições ambientais favoráveis ao desenvolvimento da doença (Tabela 2). Apesar de não ter sido realizado um monitoramento diário das condições climáticas no interior da casa-de-vegetação, por limitações físicas, foram observadas temperaturas entre 35 e $40^{\circ} \mathrm{C}$ durante a condução deste ensaio. Houve influência significativa das doses de uréia aplicadas em cobertura na AACPMC somente no ensaio com a cultivar IAC Carioca Pyatã, havendo o ajuste da equação linear y $=0,0246 x+18,041\left(R^{2}=0,6768\right)$ aos valores
Tabela 1. Matéria seca da parte aérea (g) de plantas de feijoeiro das cultivares IPR 88 - Uirapuru, IAC Carioca Pyatã e SCS 202 - Guará, aos 10 dias após a semeadura.

\begin{tabular}{cccc}
\hline $\begin{array}{c}\text { Doses de N } \\
\left(\mathbf{k g . h a}^{-1}\right)^{1}\end{array}$ & $\begin{array}{c}\text { IAC Carioca Pyatã } \\
(\mathbf{g})^{*}\end{array}$ & $\begin{array}{c}\text { IPR 88 - } \\
\text { Uirapuru } \\
(\mathbf{g})^{*}\end{array}$ & $\begin{array}{c}\text { SCS 202 - } \\
\text { Guará } \\
(\mathbf{g})^{*}\end{array}$ \\
\hline 50 & $0,74^{2}$ n.s. $^{3}$ & 0,77 n.s. & 0,89 n.s. \\
75 & 0,71 & 0,77 & 0,92 \\
100 & 0,63 & 0,74 & 0,86 \\
125 & 0,70 & 0,79 & 0,90 \\
150 & 0,74 & 0,75 & 0,96 \\
C.V. $(\%)$ & 10,90 & 9,84 & 10,13 \\
\hline
\end{tabular}

${ }^{1} \mathrm{~N}$ sob forma de uréia, aplicado em cobertura; ${ }^{2}$ Amostra composta por 15 plantas de feijoeiro, distribuídas em cinco vasos com $8 \mathrm{~L}$ de solo; ${ }^{3} \mathrm{~ns}=$ teste $\mathrm{F}$ não significativo a $5 \%$ de probabilidade

obtidos (Figura 1). Assim, infere-se que a cada quilo de $\mathrm{N}$ em cobertura aplicado na cultivar IAC Carioca Pyatã, houve um aumento correspondente a 18,06 unidades de AACPMC, indicando que doses crescentes de $\mathrm{N}$ favoreceram o progresso da murcha-de-curtobacterium no tempo. Nas outras cultivares avaliadas, a murcha-de-curtobacterium não foi influenciada pelas doses de $\mathrm{N}$ aplicadas em cobertura. Aventa-se a hipótese que apenas o genótipo exerceu influência nestes resultados, uma vez que o baixo teor de matéria orgânica $(1,0 \%)$ no solo empregado neste ensaio e a pouca nodulação observada nas raízes das cultivares, na última avaliação dos sintomas, não interferiram na resposta das plantas ao $\mathrm{N}$ mineral aplicado. Avaliandose as notas médias de severidade aos 5 DAI, pode-se verificar que apenas as plantas da cultivar IPR 88 - Uirapuru, adubadas com $75 \mathrm{~kg} \cdot \mathrm{ha}^{-1}$ de $\mathrm{N}$, apresentaram-se suscetíveis a $C$. $f$. pv. flaccumfaciens. Aos 10 DAI, as plantas da cultivar SCS $202-$ Guará que foram submetidas à dose recomendada de N (100 $\mathrm{kg} \cdot \mathrm{ha}^{-1}$ ) apresentaram-se com a menor nota média de severidade. Nesta data de avaliação e nas subseqüentes, as cultivares SCS 202 - Guará e IPR 88 - Uirapuru mostraram-se com notas de severidade elevadas, enquanto que somente as plantas da cultivar IAC Carioca Pyatã foram resistentes. A redução da severidade da murcha-de-curtobacterium, observada nas plantas da 'IAC Carioca Pyatã' entre as avaliações realizadas aos 15 e 20 DAI, foi em decorrência da emissão de folhas novas. Numericamente, observou-se maior severidade nas plantas desta cultivar submetidas à maior dose de N. De uma forma geral, a influência da adubação na severidade de doenças de plantas pode ser mascarada por reações de extrema resistência ou suscetibilidade (30). Contudo, os resultados obtidos neste trabalho mostraram que somente nas plantas da cultivar IAC Carioca Pyatã, resistente à murcha-de-curtobacterium (13), foi possível verificar que a AACPMC foi alterada conforme as doses de N. Estes resultados concordaram, em parte, com aqueles obtidos por Long et al. (11), que verificaram o efeito da adubação nitrogenada no progresso da brusone em uma cultivar de arroz altamente resistente, quatro moderadamente resistentes e três suscetíveis em Arkansas, E.U.A. Foi constatado que a aplicação de doses de $\mathrm{N}$ acima do recomendado aumentou a incidência e 
a severidade da doença na maioria das cultivares, exceto na Kaybonnet, altamente resistente.

Em contraste com o que foi encontrado neste ensaio, Canaday \& Wyatt (3) avaliaram o efeito de doses de $\mathrm{N}$ na podridão bacteriana do brócolis, causada por Pseudomonas marginalis,

Tabela 2. Severidade e AACPMC nas cultivares IAC Carioca Pyatã, IPR Uirapuru e SCS 202 - Guará, em função de diferentes doses de N, aplicadas em cobertura e sob forma de uréia.

\begin{tabular}{|c|c|c|c|c|c|c|c|}
\hline \multicolumn{8}{|c|}{ Severidade } \\
\hline $\begin{array}{l}\text { Doses de N } \\
\left(\mathrm{kg}^{\prime} \mathrm{ha}^{-1}\right)\end{array}$ & $\stackrel{5}{\mathbf{D A I}}$ & $\begin{array}{c}10 \\
\text { DAI }\end{array}$ & $\begin{array}{c}15 \\
\text { DAI }\end{array}$ & $\begin{array}{c}20 \\
\text { DAI }\end{array}$ & $\begin{array}{c}25 \\
\text { DAI }\end{array}$ & Reação $^{2}$ & $\mathbf{A A C P M C}^{3}$ \\
\hline \multicolumn{8}{|c|}{ IAC Carioca Pyatã } \\
\hline 50 & 0,00 & 1,07 & 1,00 & 1,00 & 1,80 & $\mathrm{R}$ & $19,84^{*}$ \\
\hline 75 & 0,00 & 1,07 & 1,00 & 1,00 & 1,80 & $\mathrm{R}$ & 19,84 \\
\hline 100 & 0,00 & 1,00 & 1,00 & 1,00 & 1,87 & $\mathrm{R}$ & 19,67 \\
\hline 125 & 0,00 & 1,20 & 1,00 & 1,00 & 1,87 & $\mathrm{R}$ & 20,66 \\
\hline 150 & 0,00 & 1,53 & 1,00 & 1,00 & 1,93 & $\mathrm{R}$ & 22,50 \\
\hline $\mathrm{CV}(\%)$ & & & & & & & 7,32 \\
\hline \multicolumn{8}{|c|}{ IPR 88 - Uirapuru } \\
\hline 50 & 1,87 & 9,00 & 9,00 & 9,00 & 9,00 & $\mathrm{~S}$ & 162,17 n.s. \\
\hline 75 & 2,87 & 9,00 & 9,00 & 9,00 & 9,00 & $\mathrm{~S}$ & 164,67 \\
\hline 100 & 1,86 & 8,86 & 9,00 & 9,00 & 9,00 & $\mathrm{~S}$ & 161,46 \\
\hline 125 & 1,13 & 9,00 & 9,00 & 9,00 & 9,00 & $\mathrm{~S}$ & 160,33 \\
\hline 150 & 1,93 & 9,00 & 9,00 & 9,00 & 9,00 & $\mathrm{~S}$ & 162,34 \\
\hline $\mathrm{CV}(\%)$ & & & & & & & 2,10 \\
\hline \multicolumn{8}{|c|}{ SCS 202 - Guará } \\
\hline 50 & 0,80 & 6,19 & 9,00 & 8,87 & 8,73 & $\mathrm{~S}$ & 144,10 n.s. \\
\hline 75 & 0,80 & 3,53 & 8,20 & 9,00 & 8,26 & S & 126,31 \\
\hline 100 & 0,13 & 2,77 & 7,93 & 8,87 & 7,58 & S & 117,12 \\
\hline 125 & 0,27 & 5,00 & 8,60 & 9,00 & 7,99 & $S$ & 133,65 \\
\hline 150 & 0,13 & 4,40 & 8,73 & 8,73 & 7,99 & S & 129,64 \\
\hline $\mathrm{CV}(\%)$ & & & & & & & 11,14 \\
\hline
\end{tabular}

${ }^{1}$ Dias após a inoculação; ${ }^{2}$ Aos 25 DAI; R=Resistente; $\mathrm{S}$ = Suscetível; ${ }^{3}$ Área abaixo da curva da murcha-de-curtobacterium; ${ }^{4}$ Média de cinco repetições; *Teste $\mathrm{F}$ significativo a $5 \%$ de probabilidade; $\mathrm{ns}=$ teste $\mathrm{F}$ não significativo a $5 \%$ de probabilidade.

nas cultivares Premium Crop. (suscetível) e Shogum (resistente). Observou-se que doses crescentes de nitrogênio incrementaram a incidência e a severidade da doença somente na cultivar suscetível. Em recentes experimentos, foi verificado que os sintomas do crestamento bacteriano comum do feijoeiro tenderam a diminuir em função do aumento do $\mathrm{N}$ em solução nutritiva tanto na cultivar IAC Carioca, suscetível, quanto na IAPAR 14, resistente a Xanthomonas axonopodis pv. phaseoli $(1,2)$. Assim, este ensaio indicou que não se pode generalizar o comportamento de doenças de plantas em função da adubação nitro-

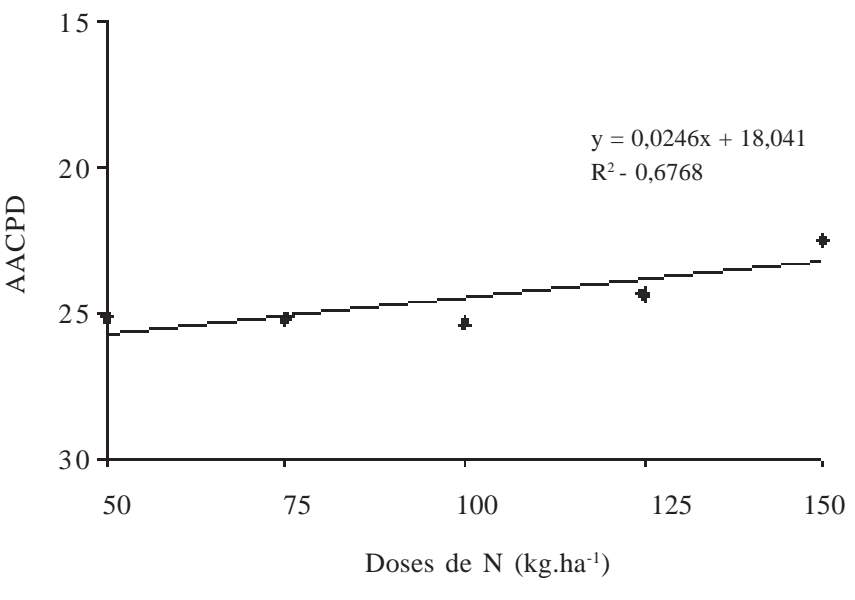

Figura 1. Influência de doses de $\mathrm{N}$ na área abaixo da curva do progresso da murcha-de-curtobacterium (AACPMC), em feijoeiro cultivar Pyatã inoculado com $C$. flaccumfaciens pv.flaccumfaciens.

genada. O aumento da severidade de doenças de plantas em decorrência de doses elevadas de $\mathrm{N}$ também foi observado em outros patossistemas $(18,22,25)$. Empregando-se a cultivar Higrade, cultivada em solução nutritiva, Rickard \& Walker (17) relataram que não houve consistência nos resultados obtidos mediante a avaliação da influência de duas doses de $\mathrm{N}$ nos sintomas da murcha-de-curtobacterium. No primeiro experimento conduzido por estes autores, com o uso de inoculação no pecíolo da folha, houve tendência em aumentar a porcentagem de folhas doentes conforme o emprego da maior dose de N. Porém, ao ser repetido, a resposta foi oposta, concordando quando se procedeu a inoculação por ferimento no nó cotiledonar. Os resultados demonstrados no trabalho indicaram que a severidade da murcha-de-curtobacterium do feijoeiro, na cultivar IAC Carioca Pyatã, tendeu a se elevar conforme houve o uso de doses crescentes de N. Embora a maior dose de N empregada não ter alterado a reação desta cultivar de resistência para suscetibilidade, este resultado indica a necessidade de estudos com outros genótipos resistentes, para confirmar o observado. Além disso, indicou que o uso de doses abaixo da recomendada, o que geralmente ocorre em sistemas de produção com baixo ou nenhum emprego de insumos, pode reduzir a importância da murcha-de-curtobacterium. Esta hipótese é reforçada pelo trabalho que procurou avaliar a ocorrência da murcha-de-curtobacterium do feijoeiro em localidades do Estado de Santa Catarina e demonstrou que esta doença ocorreu em menor freqüência pequenos estabelecimentos rurais (27). Contudo, não se preconiza a aplicação de $\mathrm{N}$, em forma de adubos minerais e/ou orgânicos, em níveis abaixo dos recomendados pela análise de solo, uma vez que este nutriente está intimamente relacionado com a concentração de clorofila e a produtividade da cultura $(4,21)$.

Ao contrário do observado por Lima et al. (10), as diferentes doses de $\mathrm{N}$ não influenciaram significativamente no acúmulo de matéria seca em nenhuma das cultivares avaliadas (Tabela 3). Porém, as plantas inoculadas com C. flaccumfaciens pv.flaccumfaciens apresentaram redução na matéria seca de 57,60 a 67,63 \% (IAC Carioca Pyatã), 66,67 a 74,02 \% (SCS 202 - Guará) 
e 78,55 a 82,13\% (IPR 88 - Uirapuru), em função da dose de N aplicada. O mesmo tipo de resposta foi observado por Maringoni (2003) para a cultivar IAC Carioca Pyatã (48,53\%), aos 40 dias após a semeadura. Este menor desenvolvimento das plantas acarretaram menor concentração de $\mathrm{N}, \mathrm{P}, \mathrm{K}, \mathrm{Ca}$ e $\mathrm{Mg}$ na parte aérea, independentemente da quantidade de $\mathrm{N}$ aplicada (Tabelas 4 e 5). A quantidade de $\mathrm{N}$ na parte aérea das plantas foi significativamente influenciada pelas doses de uréia, nas plantas das três cultivares não inoculadas, aos 35 dias após a semeadura (Tabela 4). Foram ajustadas as equações lineares (IAC Carioca Pyatã e IPR 88 - Uirapuru) e quadráticas (SCS 202 Guará) aos valores deste nutriente na parte aérea dos feijoeiros (Figuras 2 e 3). O aumento das doses de $\mathrm{N}$ interferiu na quantidade dos nutrientes $\mathrm{P}, \mathrm{K}, \mathrm{Ca}$ e $\mathrm{Mg}$ apenas na parte aérea da cultivar SCS 202 - Guará, provavelmente pela maior capacidade de resposta da mesma à adubação. Silveira \& Damasceno (21) também verificaram efeito significativo de doses de $\mathrm{N}$ aplicado ao solo sobre a quantidade de $\mathrm{N}$ em feijoeiros da cultivar Carioca, em condições de campo, no Estado de Goiás. Estes atribuíram o ocorrido à quantidade de matéria seca, pois à medida que o peso da matéria seca aumentou, o mesmo ocorreu com a quantidade do nutriente na planta. Em condições de casa-de-vegetação, Biazon et al. $(1,2)$ verificaram acúmulo de $\mathrm{N}$ em folhas das cultivares IAC Carioca e IAPAR 14 em função do aumento das doses deste nutriente na solução nutritiva. Todavia, constataram que a quantidade de $\mathrm{P}, \mathrm{K}$ e $\mathrm{Mg}$ variou nos dois experimentos conduzidos com a 'IAC Carioca' e que, nos folíolos da 'IAPAR 14', houve aumento da quantidade de K e redução de $\mathrm{P}, \mathrm{Ca}$ e $\mathrm{Mg}$. Os resultados encontrados no presente trabalho mostraram aumento na quantidade de todos os nutrientes ava- liados na parte aérea dos feijoeiros. De todos os macronutrientes, Lima et al. (10) apenas verificaram aumento na quantidade de $\mathrm{P}$ na parte aérea de plantas de feijão cultivar Pérola, conduzidos em vasos contendo $15 \mathrm{~L}$, pelo incremento de doses de uréia. Conforme estes autores, o nitrogênio potencializou a absorção de $\mathrm{P}$ pelo feijoeiro. Infere-se que as diferenças observadas nestes trabalhos, a respeito da quantidade de nutrientes em plantas de feijoeiro, em função de doses de N, possam ser atribuídas às características de cada genótipo, com diferentes marchas de absorção de nutrientes e às condiçõos de cultivo e condução das plantas.

No ensaio em que as plantas foram inoculadas com $C . f$. pv. flaccumfaciens, somente foi observada interferência das doses de uréia na concentração de $\mathrm{N}$ da parte aérea na cultivar IPR 88 - Uirapuru, ajustando-se uma equação linear aos dados obtidos (Figura 4). Conforme Rosolem (19), a condição fitossanitária interfere na resposta do feijoeiro ao $\mathrm{N}$, além da região de cultivo e do clima.

Com base nos ensaios conduzidos neste trabalho, demonstrou-se que a quantidade de N, P, K, Ca e Mg na parte aérea das plantas inoculadas foi inferior àquela encontrada nas plantas não inoculadas (Tabelas 4 e 5). Tanto a maior quanto a menor dose de uréia empregada não interferiram na menor quantidade de $\mathrm{N}$ dos feijoeiros infectados. Na cultivar IAC Carioca Pyatã, houve uma redução de 41,8 (50 kg.ha $\left.{ }^{-1}\right)$ a 66,7 \% (150 kg.ha-1), na IPR 88 - Uirapuru foi de 73,1 a 80,8\% e na SCS 202 - Guará de 54,3 a 74,0 \% na quantidade de N. Estes resultados estão em concordância com os obtidos por Maringoni (12), que afirmou que as reduções dos macronutrientes são mais acentuadas nas cultivares suscetíveis do que nas resistentes à murcha-de-curtobacterium.

Tabela 3. Massa da matéria seca (g.planta-1 ${ }^{-1}$ das cultivares IPR 88 - Uirapuru, IAC Carioca Pyatã e SCS 202 - Guará em função de doses de N, aplicadas em cobertura e sob forma de uréia, aos 35 dias após a semeadura.

\begin{tabular}{|c|c|c|c|c|c|c|c|c|c|}
\hline \multirow[b]{2}{*}{ Doses de N $\left(\mathrm{kg} \cdot \mathrm{ha}^{-1}\right)$} & \multicolumn{3}{|c|}{ IPR 88 - Uirapuru* } & \multicolumn{3}{|c|}{ IAC Carioca Pyatã* } & \multicolumn{3}{|c|}{ SCS 202 - Guará* } \\
\hline & $\mathbf{T}^{1}$ & $\mathbf{I}^{2}$ & $(\%)$ & $\mathbf{T}^{1}$ & $\mathbf{I}^{2}$ & $(\%)$ & $\mathbf{T}^{1}$ & $\mathbf{I}^{2}$ & $(\%)$ \\
\hline 50 & 5,55 n.s. ${ }^{3}$ & 1,17 & 78,92 & 5,50 n.s. & 1,78 n.s. & 67,63 & 4,44 n.s. & 1,48 n.s. & 66,67 \\
\hline 75 & 6,91 & 1,34 & 80,61 & 5,86 & 1,96 & 66,55 & 5,46 & 1,57 & 71,25 \\
\hline 150 & 6,37 & 1,26 & 80,22 & 5,06 & 1,77 & 65,02 & 5,89 & 1,53 & 74,02 \\
\hline C.V. $(\%)$ & 15,14 & 12,17 & & 17,56 & 13,80 & & 15,03 & 17,77 & \\
\hline
\end{tabular}

* Média de cinco repetições; ${ }^{1}$ Testemunha; ${ }^{2}$ Inoculado com $C$. flaccumfaciens pv. flaccumfaciens; ${ }^{3}$ ns: teste F não significativo a $5 \%$ de probabilidade. 
Tabela 4. Quantidade de nitrogênio $(\mathrm{N})$, fósforo $(\mathrm{P})$, potássio $(\mathrm{K})$, cálcio $(\mathrm{Ca})$ e magnésio $(\mathrm{Mg})$ nas cultivares IPR 88 - Uirapuru, IAC Carioca Pyatã e SCS 202 - Guará, não inoculadas, em função de doses de $\mathrm{N}$, aplicadas em cobertura e sob forma de uréia, aos 35 dias após a semeadura.

\begin{tabular}{|c|c|c|c|c|c|}
\hline \multicolumn{6}{|c|}{ Quantidade de nutrientes (mg.planta ${ }^{-1}$ ) } \\
\hline $\begin{array}{l}\text { Doses de N } \\
\left(\mathrm{kg} \mathbf{h a}^{-1}\right)\end{array}$ & $\mathbf{N}$ & $\mathbf{P}$ & $\mathbf{K}$ & $\mathbf{C a}$ & Mg \\
\hline \multicolumn{6}{|c|}{ IAC Carioca Pyatã } \\
\hline 50 & $165,2^{*}$ & 7,4 n.s. & 100,6 n.s. & 99,2 n.s. & 29,4 n.s. \\
\hline 75 & 222,6 & 8,7 & 112,8 & 109,3 & 33,5 \\
\hline 100 & 241,6 & 8,1 & 106,4 & 95,2 & 29,5 \\
\hline 125 & 274,2 & 7,7 & 106,9 & 101,8 & 32,1 \\
\hline 150 & 287,5 & 7,1 & 96,1 & 100,5 & 32,0 \\
\hline $\mathrm{CV}(\%)$ & 10,01 & 25,08 & 21,03 & 20,37 & 17,27 \\
\hline \multicolumn{6}{|c|}{ IPR 88 - Uirapuru } \\
\hline 50 & $203,3^{*}$ & 11,6 n.s & 135,4 n.s & $143,8 \mathrm{n} . \mathrm{s}$ & 36,8 n.s \\
\hline 75 & 263,6 & 16,0 & 169,9 & 171,1 & 47,3 \\
\hline 100 & 314,6 & 17,6 & 181,8 & 174,1 & 48,4 \\
\hline 125 & 292,8 & 13,7 & 155,2 & 147,7 & 41,8 \\
\hline 150 & 361,4 & 16,2 & 158,8 & 150,4 & 43,9 \\
\hline $\mathrm{CV}(\%)$ & 7,17 & 18,79 & 16,35 & 16,34 & 15,35 \\
\hline \multicolumn{6}{|c|}{ SCS 202 - Guará } \\
\hline 50 & $142,9 * *$ & $5,62 *$ & $93,0 *$ & $90,6^{*}$ & $30,1 * *$ \\
\hline 75 & 206,3 & 8,50 & 115,0 & 118,3 & 39,0 \\
\hline 100 & 240,3 & 7,39 & 111,0 & 117,0 & 38,8 \\
\hline 125 & 290,6 & 8,69 & 124,9 & 132,0 & 41,9 \\
\hline 150 & 309,5 & 8,80 & 123,0 & 131,8 & 43,2 \\
\hline $\mathrm{CV}(\%)$ & 7,18 & 18,79 & 13,73 & 11,93 & 9,66 \\
\hline
\end{tabular}

${ }^{1}$ Média de cinco repetições; * Teste $\mathrm{F}$ significativo a $1 \%$ de probabilidade; ** Teste $\mathrm{F}$ significativo a $5 \%$ de probabilidade; ns: teste $\mathrm{F}$ não significativo a $5 \%$ de probabilidade

(A)

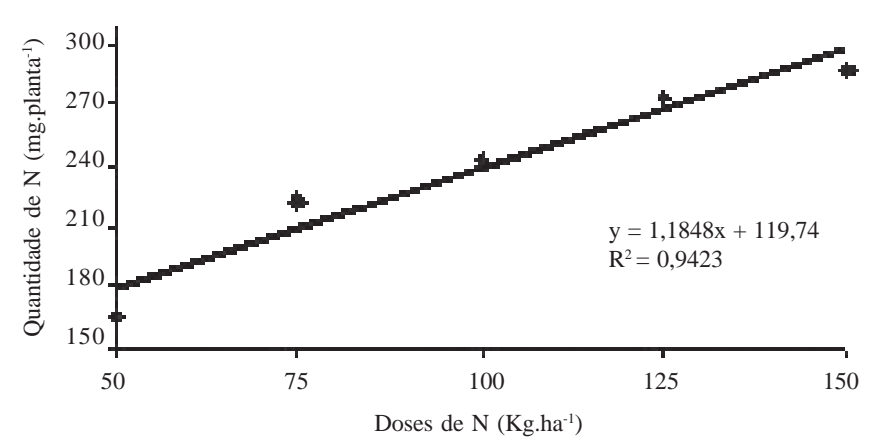

Tabela 5. Quantidade de nitrogênio $(\mathrm{N})$, fósforo $(\mathrm{P})$, potássio $(\mathrm{K})$, cálcio $(\mathrm{Ca})$ e magnésio $(\mathrm{Mg})$ nas cultivares IPR 88 - Uirapuru, IAC Carioca Pyatã e SCS 202 - Guará, em função de doses de N, aplicadas em cobertura e sob forma de uréia, aos 25 dias após a inoculação com C. flaccumfaciens pv. flaccumfaciens.

\begin{tabular}{|c|c|c|c|c|c|}
\hline \multicolumn{6}{|c|}{ Quantidade de nutrientes (mg.planta ${ }^{-1}$ ) } \\
\hline $\begin{array}{l}\text { Doses de } \\
\text { N }\left(\text { kg.ha }^{-1}\right)\end{array}$ & $\mathbf{N}$ & $\mathbf{P}$ & $\mathbf{K}$ & $\mathrm{Ca}$ & Mg \\
\hline \multicolumn{6}{|c|}{ IAC Carioca Pyatã } \\
\hline 50 & 96,1 n.s. & 5,4 n.s. & 37,5 n.s. & 49,9 n.s. & 14,9 n.s. \\
\hline 75 & 110,0 & 6,5 & 41,1 & 54,3 & 16,0 \\
\hline 100 & 119,8 & 6,9 & 41,6 & 55,4 & 17,5 \\
\hline 125 & 101,5 & 5,9 & 37,3 & 47,4 & 14,8 \\
\hline 150 & 95,8 & 5,7 & 30,9 & 45,7 & 14,2 \\
\hline $\mathrm{CV}(\%)$ & 13,83 & 16,58 & 17,17 & 17,00 & 14,60 \\
\hline \multicolumn{6}{|c|}{ IPR 88 - Uirapuru } \\
\hline 50 & $54,6^{*}$ & 2,7 n.s. & 22,5 n.s. & 30,9 n.s. & 8,4 n.s. \\
\hline 75 & 66,6 & 3,2 & 24,1 & 35,1 & 10,1 \\
\hline 100 & 62,3 & 2,8 & 21,4 & 31,1 & 9,1 \\
\hline 125 & 71,6 & 3,0 & 23,0 & 31,9 & 9,3 \\
\hline 150 & 69,3 & 2,8 & 22,2 & 29,9 & 8,8 \\
\hline $\mathrm{CV}(\%)$ & 12,66 & 20,37 & 17,05 & 13,60 & 12,78 \\
\hline \multicolumn{6}{|c|}{ SCS 202 - Guará } \\
\hline 50 & 65,3 n.s. & 4,4 n.s. & 27,6 n.s. & 34,4 n.s. & 11,2 n.s. \\
\hline 75 & 79,0 & 4,8 & 29,5 & 39,0 & 13,3 \\
\hline 100 & 81,2 & 4,6 & 26,4 & 37,5 & 12,8 \\
\hline 125 & 82,2 & 4,6 & 26,5 & 33,0 & 11,7 \\
\hline 150 & 80,5 & 4,0 & 25,2 & 34,3 & 12,8 \\
\hline $\mathrm{CV}(\%)$ & 22,07 & 22,68 & 19,28 & 18,21 & 17,43 \\
\hline
\end{tabular}

${ }^{1}$ Média de cinco repetições; ns: teste F não significativo a 5\% de probabilidade; * Teste $\mathrm{F}$ significativo a $5 \%$ de probabilidade.

(B)

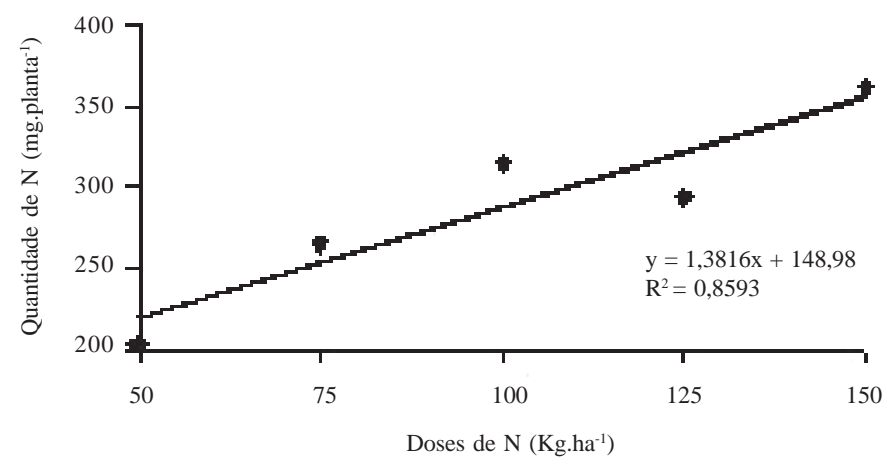

Figura 2. Quantidade de N na parte aérea de feijoeiros cv. Pyatã (A) e IPR 88 - Uirapuru (B), não inoculados com C. f. pv. flaccumfaciens, em função de doses de $\mathrm{N}$, aos 35 dias após a inoculação. 
(A)

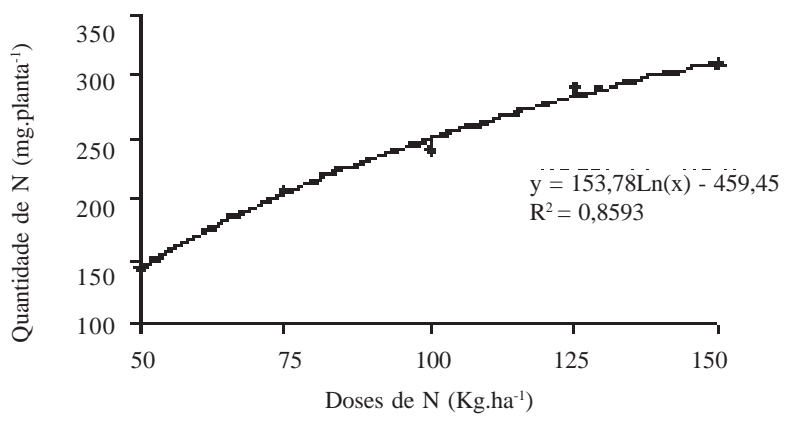

(C)

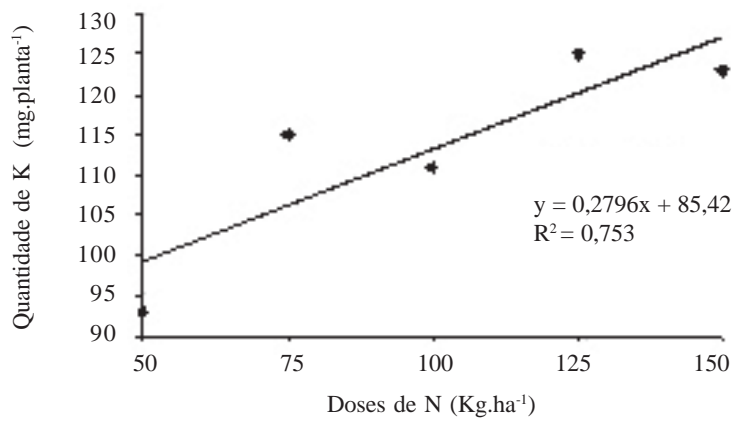

(E)
(B)

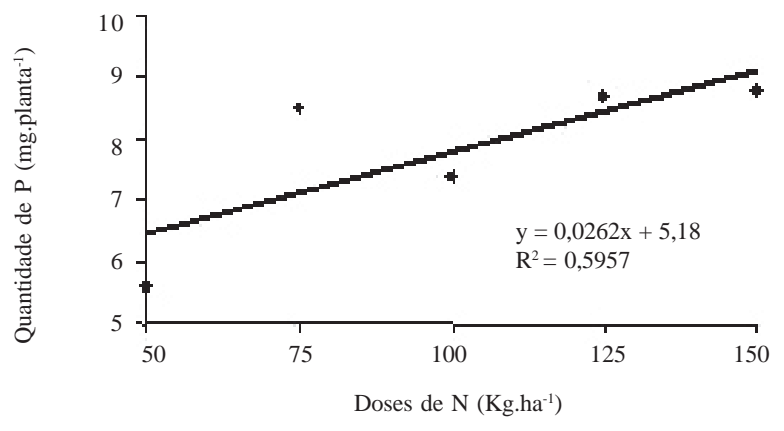

(D)

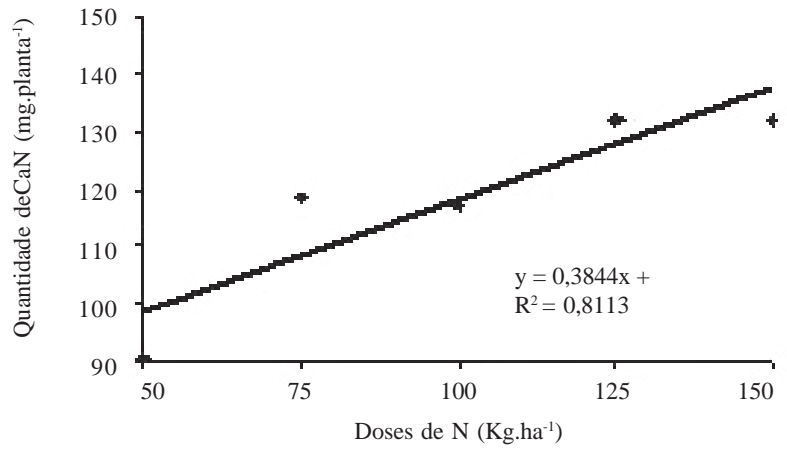

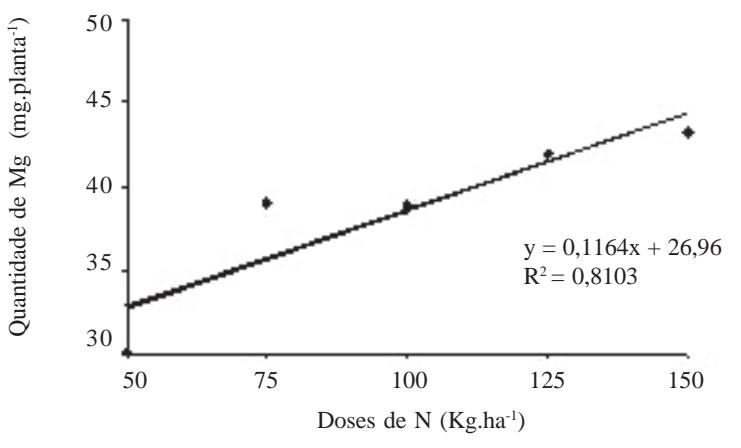

Figura 3. Quantidade de nitrogênio (A), fósforo (B), potássio (C), cálcio (D) e magnésio (E) na parte aérea de feijoeiro cv. SCS 202 - Guará, não inoculado com C. flaccumfaciens pv. flaccumfaciens, em função de doses de N, aos 35 dias após a inoculação.

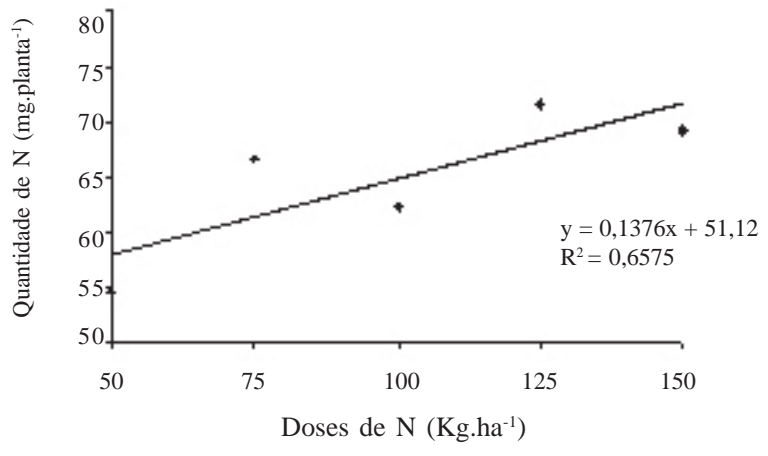

Figura 4. Quantidade de N na parte aérea de feijoeiro cv. IPR 88 Uirapuru inoculado com C. flaccumfaciens pv. flaccumfaciens, em função de doses de N, aos 35 dias após a inoculação.

\section{REFERÊNCIAS BIBLIOGRÁFICAS}

1. Biazon, V.L.; Maringoni, A.C.; Grassi Filho, H. Efeito de cálcio e de nitrogênio na suscetibilidade da cultivar de feijoeiro IAC-Carioca ao crestamento bacteriano comum. Summa Phytopathologica, Jaboticabal, v.26, n.3, p.295-299, 2000.

2. Biazon, V.L.; Maringoni, A.C.; Grassi Filho, H. Influência de cálcio e de nitrogênio nas quantidade de macronutrientes foliares e na suscetibilidade do feijoeiro Iapar 14 ao crestamento bacteriano comum. Summa Phytopathologica, Botucatu, v.30, n.3, p.320-323, 2004.

3. Canaday, C.H.; Wyatt, J.E. Effects of nitrogen fertilization on bacterial soft rot in two broccoli cultivars, one resistant and one susceptible to the disease. Plant Disease, St. Paul, v.76, n.10, p.989-991, 1992.

4. Carvalho, M.A.C.; Furlani Junior, E.; Arf, O.; Sá, M.E.; Pauli- 
no, H.B.; Buzetti, S. Doses e épocas de aplicação de nitrogênio e teores foliares deste nutriente e de clorofila em feijoeiro. Revista Brasileira de Ciência do Solo, Viçosa, v.27, n.3, p.445-450, 2003.

5. Comissão de Fertilidade do Solo - RS/SC. Recomendações de adubação e de calagem para os estados do Rio Grande do Sul e de Santa Catarina. 3.ed. Passo Fundo: SBCS-Núcleo Regional Sul, 1994. 224 p.

6. Engelhard, A.W. Historical highlights and prospects for the future. In:__. (Ed.) Soilborne plant pathogens: management of diseases with macro-and microelements. St. Paul: APS Press, 1990. p.9-17

7. Hall, R. Compendium of bean diseases. St.Paul: APS Press, 1991.73p.

8. Hedges, F. A bacterial wilt of bean caused by Bacterium flaccumfaciens. Science, v.55, p.433-434, 1922.

9. Leite JR., R.P.; Behlau, F. Caracterização da murcha-de-curtobacterium do feijoeiro no Paraná. In: Reunião sulbrasileira de feijão, 5. 2001, Londrina. Anais ... Londrina: Iapar, 2001. p.50-54.

10. Lima, E.V.; Aragão, C.A.; Morais, O.M.; Tanaka, R.; Grassi Filho, H. Adubação NK no desenvolvimento e na concentração de macronutrientes no florescimento do feijoeiro. Scientia Agricola, Piracicaba, v.58, n.1, p.125-129, 2001.

11. Long, D.H.; Lee, F.N.; Tebeest, D.O. Effect of nitrogen fertilization on disease progress of rice blast on susceptible and resistant cultivars. Plant Disease, St. Paul, v.84, n.4, p.403409, 2000 .

12. Maringoni, A.C. Alterações nos teores de macronutrientes em plantas de feijoeiro infectadas por Curtobacterium flaccumfaciens pv. flaccumfaciens. Ciência e Agrotecnologia, Lavras, v.27, n.1, p.217-222, 2003.

13. Maringoni, A.C. Comportamento de cultivares de feijoeiro comum à murcha-de-curtobacterium. Fitopatologia Brasileira, Fortaleza, v.27, n.2, p.157-162, 2002.

14. Maringoni, A.C.; Rosa, E.F. Ocorrência de Curtobacterium flaccumfaciens $p v$. flaccumfaciens em feijoeiro no Estado de São Paulo. Summa Phytopathologica, Jaboticabal, v.23, n. 1/2, p.160-162, 1997.

15. Pozza, A.A.A.; Martinez, H.E.P.; Caixeta, S.L.; Cardoso, A.A.; Zambolim, L.; Pozza, E.A. Influência da nutrição mineral na intensidade da mancha-de-olho-pardo em mudas de cafeeiro. Pesquisa Agropecuária Brasileira, Brasília, v.36, n.1, p.55-60, 2001.

16. Raij, B.V. Fertilidade do solo e adubação. Piracicaba: Ceres, Potafos, 1991. 343p.

17. Rickard, S.F.; Walker, J.C. Mode of inoculation and host nutrition in relation to bacterial wilt of bean. Phytopathology, St. Paul, v.55, p.174-178, 1965.

18. Rodrigues, F.A.; Carvalho, E.M.; Vale, F.X.R. Severidade da podridão-radicular de Rhizoctonia do feijoeiro influenciada pela calagem e pelas fontes e doses de nitrogênio. Pesquisa
Agropecuária Brasileira, Brasília, v.37, n.9, p.1247-1252, 2002.

19. Rosolem, C.A. Calagem e adubação mineral. In: Araujo, R.S.; Rava, C.A.; Stone, L.F.; Zimmermann, M.J.O. (Coord.). Cultura do feijoeiro comum no Brasil. Piracicaba: Potafos, 1996. p.353-390.

20. Rosolem, C.A. Nutrição e adubação do feijoeiro. Piracicaba: Associação Brasileira para Pesquisa da Potassa e do Fosfato, 1987.93p. (Boletim Técnico, n.8).

21. Silveira, P.M.; Damasceno, M.A. Doses e parcelamento de $\mathrm{K}$ e de $\mathrm{N}$ na cultura do feijoeiro irrigado. Pesquisa Agropecuária Brasileira, Brasília, v.28, n.11, p.1269-1276, 1993.

22. Slaton, N.A.; Gbur, E.E.; Cartwright, R.D.; Delong, R.E.; Norman, R.J.; Brye, K.R. Grain yield and kernel smut of rice as affected by preflood and midseason nitrogen fertilization in Arkansas. Agronomy Journal, Madison, v.96, p.91-99, Jan-Feb. 2004.

23. Soares, R.M.; Maringoni, A.C. Efeito de acibenzolar-S-methyl sobre a germinação e desempenho de sementes de feijoeiro e na indução de resistência à murcha de curtobacterium. Summa Phytopathologica, Botucatu, v.28, n.1, p.4145, 2002.

24. Soares, R.M.; Maringoni, A.C.; Lima, G.P.P. Ineficiência de acibenzolar-S-methyl na indução de resistência de feijoeiro comum à murcha-de-curtobacterium. Fitopatologia Brasileira, v.29, n.4, p.373-377, Jul-Ago. 2004.

25. Tanaka, M.A.S.; Passos, F.A.; Feitosa, C.T.; Tanaka, R.T. Efeito da adubação mineral e orgânica do morangueiro sobre a antracnose do rizoma, causada por Colletotrichum fragariae. Summa Phytopathologica, Jaboticabal, v.28, n.3, p.236-241, 2002.

26. Tedesco, M.J.; Gianello, C.; Gissani, C.A.; Bohnen, H.; Volkweiss, S.J. Análises de solo, plantas e outros materiais. 2.ed., Porto Alegre: UFRGS, 1995. 174p. (Boletim Técnico, n.5).

27. Theodoro, G.F.; Maringoni, A.C. Murcha-de-curtobacterium do feijoeiro no Estado de Santa Catarina e reação de genótipos à Curtobacterium flaccumfaciens pv. flaccumfaciens. Summa Phytopathologia, Botucatu, v.32, n.1, p. 34-41, 2006.

28. Uesugi, C.H.; Freitas, M.A.; Menezes, J.R. Ocorrência de Curtobacterium flaccumfaciens pv. flaccumfaciens em feijoeiro, em Goiás e no Distrito Federal. Fitopatologia Brasileira, Fortaleza, v.28, n.3, p.324, 2003.

29. Yamazaki, H.; Ishizuka, O.; Hoshina, T. Relationship between resistance to bacterial wilt and nutrient uptake in tomato seedlings. Soil Science and Plant Nutrition, v.42, n.1, p.203208, 1996.

30. Zambolim, L.; Ventura, J.A. Resistência a doenças induzida pela nutrição mineral das plantas. Revisão Anual de Patologia de Plantas, Passo Fundo, v.1, p.275-318, 1993. 